\title{
Dos Números aos Gráficos e Mapas - Oficinas de Tratamento da Informação Geográfica
}

\author{
From Numbers to Graphs and Maps -Workshops on Geographic Information \\ Treatment
}

\section{De Números a Gráficos y Mapas - Talleres de Tratamiento de Información Geográfica}

\author{
Luana Writzl ${ }^{1}$ \\ Lisane Regina Vidal Conceição² \\ Eduardo Schiavone Cardoso ${ }^{3}$
}

\begin{abstract}
RESUMO: Através de recursos didáticos variados é possível tornar as aulas de geografia mais atrativas para os alunos da educação básica. Quando os assuntos são poucos discutidos e vistos como uma barreira de aprendizagem pelos educandos, como é o caso da interpretação e construção de tabelas, gráficos e mapas, alternativas didáticas devem ser apresentadas. Este trabalho relata a aplicação de oficinas que possibilitaram um melhor desenvolvimento desses assuntos por parte dos educandos, bem como a construção de debates sobre os dados que foram trabalhados. Tais dados foram referentes à produção e ao consumo de soja e da carne em nível brasileiro e global. As oficinas foram realizadas com turmas do segundo e terceiro ano do ensino médio e contribuíram com aulas menos tradicionais. Possibilitaram uma visão para as perspectivas futuras, de que haja maior abundância de atividades relacionadas ao tratamento e interpretação de dados nas aulas de geografia, visto as dificuldades dos alunos frente a isso.
\end{abstract}

PALAVRAS-CHAVE: Geografia. Informação. Ensino.

ABSTRACT: The use of varied teaching resources contributes to more attractive geography classes for basic education students. When the topics are not sufficiently discussed and when they are considered a learning barrier to the students, for example the interpretation as well as the drawing of charts, graphs and maps, pedagogical alternatives must be presented. This study describes the workshops that enabled a better development of these topics by the students and also the debate about the data which were used. The data were related with the production and the consumption of soybeans and meat,

\footnotetext{
1 Universidade Federal de Santa Maria, Av. Roraima, 1000, Bairro Camobi, Santa Maria - RS, CEP: 97105 - 900. luanawritzl@yahoo.com.br.

2 Universidade Federal de Santa Maria, Av. Roraima, 1000, Bairro Camobi, Santa Maria - RS, CEP: 97105 - 900. lisanevidal@gmail.com.

3 Universidade Federal de Santa Maria, Av. Roraima, 1000, Bairro Camobi, Santa Maria - RS, CEP: 97105 - 900. educard@smail.ufsm.br.
} 
nationally and globally. The workshops were offered for second and third year High School groups and it permitted less traditional classes. It showed the future perspectives on more activities involving treatment and interpretation of data in the geography lessons considering that the students have difficulties dealing with it.

KEYWORDS: Geography. Information. Teaching.

RESUMEN: A través de diversos recursos didácticos es posible hacer que las clases de geografía sean más atractivas para los estudiantes de educación básica. Cuando los temas son pocos discutidos y vistos como una barrera de aprendizaje para los alumnos, como la interpretación y construcción de tablas, cuadros y mapas, se deben presentar alternativas didácticas. Este documento informa sobre la aplicación de talleres que permitieron a los estudiantes desarrollar mejor estos temas, así como a desarrollar debates sobre los datos en los que se trabajó. Estos datos se refieren a la producción y el consumo de soja y carne a nivel brasileño y global. Los talleres se llevaron a cabo con clases de segundo y tercer año de escuela secundaria y contribuyeron con clases menos tradicionales. Brindaron una visión de las perspectivas futuras, de que hay una mayor abundancia de actividades relacionadas con el tratamiento e interpretación de datos en las clases de geografía, dadas las dificultades de los estudiantes en este sentido.

PALABRAS-CLAVE: Geografía. Información. Docencia.

\section{INTRODUÇÃO}

A disseminação de informações pela mídia faz com que cresçam possibilidades de conhecer ocorrências dos mais variados tipos e em praticamente todos os lugares do mundo.

Dessa forma, pela ampla área da qual a geografia se dedica a pesquisar, torna-se necessáriorefletir acerca de certas informações, usá-las e transmiti-las quando essas forem de relevância. Assim, Lacoste (1988, p. 254) afirma ainda: "O mundo é ininteligível para quem não tem um mínimo de conhecimentos geográficos". Transmitir esses conhecimentos são papeis fundamentais dos educadores para com os educandos.

No ensino básico, torna-se necessáriamaior abundância de atividades relacionadas ao tratamento e interpretação de informações, afim de conhecer os acontecimentos globais e construir aulas que viabilizem aos educandos debates que enalteçam sua criticidade e os ajudem a tornarem-se leitores de informações.Nesse sentido, a cartografia tem um papel fundamental (SANTOS et al., 2011).

As primeiras formas de transmitir representações do espaço vieram através da cartografia, conforme o que cada sociedade refletia em seus aspectos culturais. Joly (1997, p. 31) afirma que:

Os homens sempre procuraram conservar a memória dos lugares e dos caminhos úteis às suas ocupações. Aprenderam a gravar os seus detalhes em placas de argila, madeira ou metal, ou a desenhá-los nos tecidos, nos papiros e nos pergaminhos. Assim, apareceram no Egito, na Assíria, na Fenícia e na China os primeiros esboços cartográficos. 
Através da linguagem cartográfica é possível representar diversos tipos de informações, como afirma Francischett, 2004, p. 7:

A representação do espaço geográfico pode-se dar através de cartas, plantas, croquis, mapas, globos, fotografias, imagens de satélites, gráficos, perfis topográficos, maquetes, textos e outros meios que utilizam a linguagem cartográfica. A função dessa linguagem é a comunicação de informações sobre o espaço, daí a necessidade de haver uma situação comunicativa (exposição e divulgação dos trabalhos) para que a atividade seja significativa e ocorra aprendizagem e avaliação do processo, além de contribuir para que mais pessoas tenham acesso ao conhecimento.

O presente estudo é resultado de um projeto financiado pelo Programa de Licenciaturas (PROLICEN), instituído pela Universidade Federal de Santa Maria (UFSM). O trabalho foi realizado no Instituto Estadual Luiz Guilherme Prado Veppo. A escola fica localizada no bairro Tomazetti, na cidade de Santa Maria, RS, conforme a Figura 1.

Figura 1 - Mapa de localização da escola

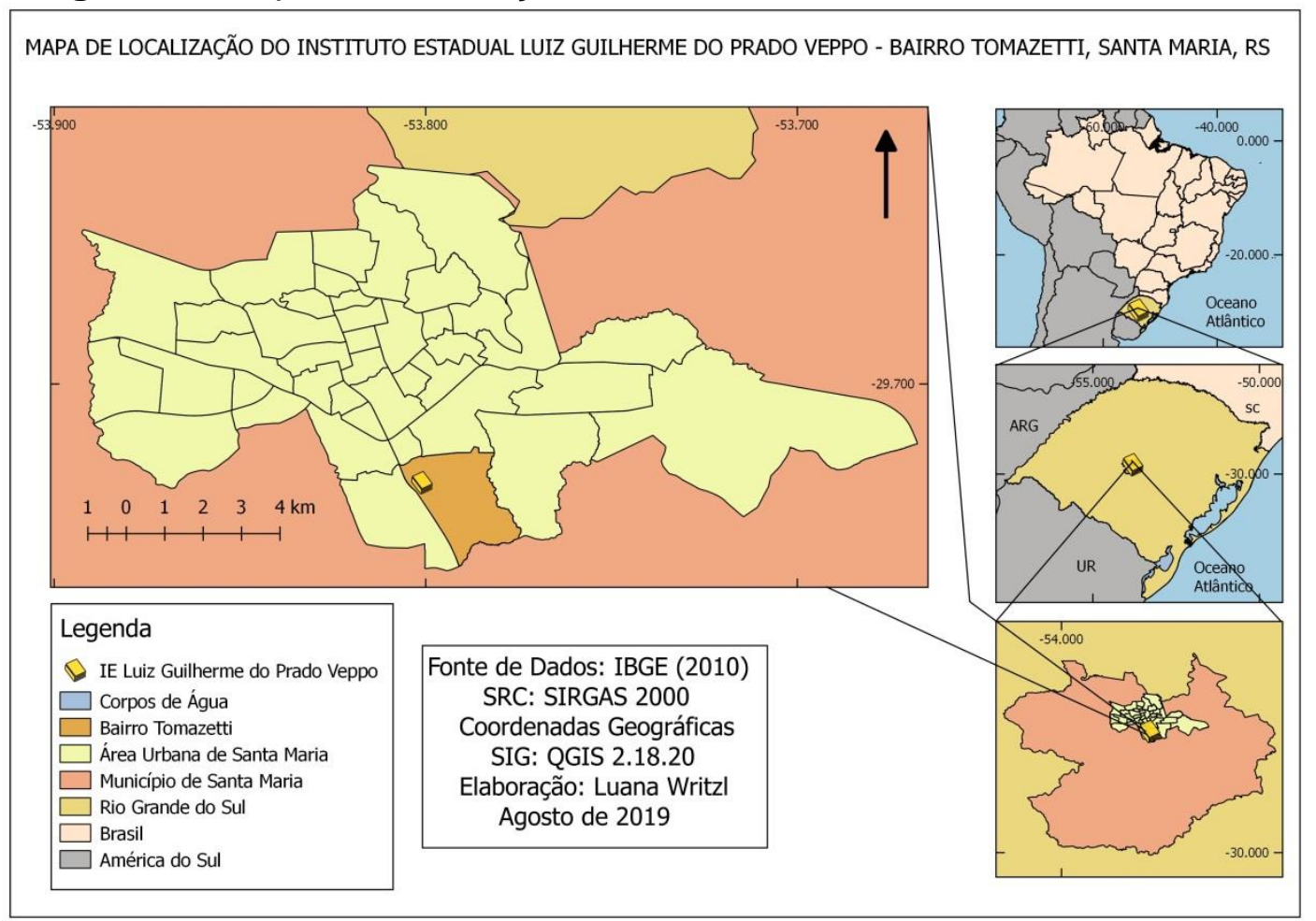

Fonte: IBGE (2019).

O bairro onde a escola se localiza é conhecido por enfrentar problemas relacionados à infraestrutura. A escola surgiu após os moradores da comunidade da Zona Sul reivindicar sua criação para que os alunos pudessem cursar o ensino médio. Em 2010, a escola foi inaugurada após sete anos de espera. Nesse tempo, ela passou a identificar os moradores 
locais com a finalidade de construir uma proposta adequada para a realidade local (INSTITUTO ESTADUAL LUIZ GUILHERME DO PRADO VEPPO, 2018).

Em conjunto com a comunidade, a escola construiu um projeto político pedagógico diferente da maioria das escolas, e busca atualmente conscientizar os alunos para que possam entender sua participação no mundo atual.

Dessa forma, o currículo da escola é formado por um corpo docente que atua por áreas de conhecimento, no qual os professores colaboram em conjunto em sala de aula. A disciplina de geografia está inserida com a história, filosofia e sociologia, na área de ciências humanas e suas tecnologias.

O objetivo desse trabalho foi de realizar oficinas didáticas pedagógicas para despertar o interesse na leitura, tratamento e interpretação de dados geográficos para alunos do ensino médio regular que cursam o $2^{\circ}$ ano noturno e $3^{\circ}$ ano diurno. Além disso, a interdisciplinaridade que esse assunto promove auxilia em diversas outras áreas do conhecimento, além das ciências humanas.

Também se buscou efetivar discussões em escala brasileira e global sobre os temas da produção e do consumo da soja e da carne, utilizados para a atividade, e aplicar a teoria apresentada nas aulas expositivas em situações concretas para um desenvolvimento mais aprofundado do conhecimento. Essa metodologia pode vir a favorecer perspectivas futuras de aulas práticas que venham a contribuir com aulas menos tradicionais.

\section{AS INFORMAÇÕES GEOGRÁFICAS E OS DADOS AGROPECUÁRIOS}

A construção do processo educativo vem sendo cada vez mais discutida entre educadoras e educadores que se preocupam com o futuro da educação frente aos desafios contemporâneos. Aulas que fogem do padrão tradicional fazem com que os alunos se interessem mais pelos assuntos a serem trabalhados e discutidos, ainda mais quando são aqueles em que os educandos sentem mais dificuldade de aprendizagem (SANTOS et al., 2011).

Na educação básica há uma dificuldade acentuada na interpretação de tabelas para a construção de gráficos e mapas. Sabe-se a importância desses para a formação dos educandos, pois é através deles que os alunos conseguem ler as informações, bem como tornarem-se leitores e intérpretes do mundo. Segundo Leal, Cardoso e Rocha (2013, p. 189): "Quando as informações são processadas e transmitidas através de tabelas, gráficos e mapas temáticos, o ensino de Geografia tem papel fundamental para que os indivíduos se tornem leitores, e venham a entender essas formas de exposição da informação". 
Mesmo que alguns desses assuntos sejam vistos em diversas disciplinas, como é o caso dos gráficos, a falta de atividades práticas faz com que cada vez menos esses conteúdos estejam recebendo a atenção merecida. Como abordam Silva e Melo (2017, p. 4):

Os gráficos, em muitas ocasiões, são considerados conteúdos e recursos difíceis e pouco praticados por professores e pela escola em geral. O que se percebe é que são elementos encontrados no dia-a-dia de meios de comunicação, em livros didáticos e podem ser utilizados por várias disciplinas escolares, contudo, ao mesmo tempo que a linguagem gráfica pode ser evidenciada com facilidade a sua visualização pelos alunos é dificultada, como se os gráficos não fossem importantes ou mesmo invisíveis.

Não muito diferente disso, os educandos possuem uma significativa dificuldade quando o assunto é a cartografia. Silva (2007, p. 2) ressalta que: "Às vezes, os mapas são usados para pintura ou até mesmo como meras ilustrações de um texto, deixando de ser um material pedagógico".

Existem diversas possibilidades didáticas e interativas de trabalhar esses temas na educação básica, podendo assim tornar a aula prazerosa e bem adequada com procedimentos metodológicos de recursos simples. Esses estudos auxiliam os alunos para que consigam, de uma forma prática, entender o mundo que os rodeia, podendo interpretá-lo de diversas formas, principalmente através da disciplina de geografia. Assim, é importante que os educandos possam sentir-se contemplados com atividades diferentes que prendam sua atenção, e os educadores têm um papel fundamental nesse processo (SILVA; MUNIZ, 2012).

Além disso, visto a importância das discussões geográficas acerca dos problemas socioeconômicos que estes gráficos e mapas podem estar abordando, é um desperdício não construir os diálogos e debates que essas ferramentas possibilitam. De acordo com Freire (2014, p. 28), "[...] o educador democrático não pode negar-se o dever de, na sua prática docente, reforçar a capacidade crítica do educando, sua curiosidade, sua insubmissão".

Portanto, é importante que os conteúdos a serem trabalhados possam ser usados como uma forma de reflexão crítica acerca da realidade existente, pois ela afeta de alguma forma a vida dos educandos, como é o caso do consumo da carne e da soja, que foram as questões abordadas nesse trabalho, tendo suas escalas brasileiras e mundiais.

O consumo da carne e a produção da soja causam impactos significativos globais, podendo relacionar essas questões ao agronegócio e aos impactos socioambientais das culturas. A maior parte da soja produzida é destinada a ração animal, por isso a produção de soja está quase que inteiramente ligada ao consumo de carne. Esses dois consumos estão presentes e possuem um grande papel na economia brasileira e mundial, interferindo também 
nos hábitos da população. No Atlas da Carne (HENRICH BÖLL STIFTUNG FOUNDATION, 2016, p. 16):

[...] a soja é a cultura agrícola que, globalmente, vem crescendo em ritmo mais acelerado nas últimas décadas, estimulada pelo forte aumento do consumo de carnes, principalmente nos chamados países emergentes. Estima-se que $90 \%$ da soja produzida no mundo tenha como destino a fabricação de farelo utilizado em rações animais, como fonte de proteínas.

Introduzir esses assuntos nas aulas de geografia na educação básica é de extrema importância para o desenvolvimento pessoal do aluno, visto que as reflexões acerca dos impactos da agricultura capitalista na sociedade afetam a todos os seres humanos. As questões da soja e da carne causam impactos em diversas culturas e podem suscitar diversos assuntos dentro das aulas de geografia, desde os impactos da produção de soja carregada de agrotóxicos e fertilizantes, até a alimentação da população, o agronegócio e os impactos socioambientais, que são assuntos previstos inclusive nos Parâmetros Curriculares Nacionais.

\section{SEQUÊNCIA DIDÁTICA DESENVOLVIDA}

A atividade foi realizada em dois encontros em cada uma das turmas nas aulas de ciências humanas. As turmas nas quais foram desenvolvidas as oficinas continham em média 9 alunos no $2^{\circ}$ ano e 15 alunos no $3^{\circ}$ ano.

No primeiro encontro foi entregue a cada aluno uma pasta, que continha: o plano de aula para os dois encontros, uma caneta, uma folha com as tabelas que seriam analisadas, uma folha quadriculada para a construção de gráficos e outras para anotações.

Esse encontro ficou marcado pela apresentação dos assuntos que seriam trabalhados com os alunos. Fez-se uma introdução a partir de uma aula expositiva-dialogada sobre a importância do uso de tabelas, gráficos e mapas na construção de leitores de informações geográficas que cabe muito aos educandos na educação básica.

Também foi construída uma discussão acerca dos conhecimentos prévios dos educandos sobre a soja brasileira e mundial e seus impactos na sociedade, tais como o de direcionar a produção para o fornecimento de commodities agrícolas. Dessa forma o início do diálogo contou com a seguinte reflexão retirada do Atlas da Carne (HENRICH BÖLL STIFTUNG FOUNDATION, 2016): "o que a pecuária brasileira tem a ver com a soja globalizada?", propiciando aos alunos um debate sobre essas questões, seguidas de reflexões pessoais acerca do consumo de soja e carne.

O passo seguinte foi o encaminhamento aos alunos da base para os procedimentos gráficos juntamente com suas fontes de dados oficiais extraídos do Sidra - IBGE. Dessa forma 
foram apresentadas as tabelas que eles iriam analisar e utilizar para a construção de gráficos durante o primeiro encontro (Tabelas 1 e 2).

Tabela 1 - Quantidade de bovinos abatidos, no trimestre

\section{Quantidade de bovinos abatidos, no trimestre}

\begin{tabular}{|c|c|c|}
\hline \multicolumn{3}{|l|}{ Brasil } \\
\hline \multicolumn{3}{|c|}{ Referência temporal - Total do trimestre } \\
\hline \multicolumn{3}{|l|}{ Tipo de rebanho bovino - Total } \\
\hline \multicolumn{3}{|l|}{ Trimestre } \\
\hline $1^{\circ}$ trimestre 2006 & $1^{\circ}$ trimestre 2012 & $1^{\circ}$ trimestre 2018 \\
\hline 7081252 & 7220002 & 7721584 \\
\hline
\end{tabular}

Fonte: IBGE - Pesquisa Trimestral do Abate de Animais

Fonte: IBGE (2018).

Tabela 2 - Série histórica da produção dos produtos das lavouras

\begin{tabular}{|c|c|c|c|}
\hline \multicolumn{4}{|c|}{ Variável - Produção (Toneladas) } \\
\hline \multicolumn{4}{|c|}{ Produto das lavouras -Soja } \\
\hline \multirow{2}{*}{ Grande Região } & \multicolumn{3}{|l|}{ Mês } \\
\hline & setembro 2006 & setembro 2012 & julho 2018 \\
\hline Norte & 1189290 & 2089138 & 5105006 \\
\hline Nordeste & 3466628 & 6096836 & 10875527 \\
\hline Sudeste & 4102125 & 4525588 & 8311237 \\
\hline Sul & 17732952 & 17948155 & 39038047 \\
\hline Centro-Oeste & 25890677 & 34724537 & 53075934 \\
\hline
\end{tabular}

Fonte: IBGE (2018).

Foi solicitado aos educandos que construíssem dois gráficos referentes à tabela 2, devido a discrepância dos dados das regiões. Para isso, foi exposto um exemplo no quadro referente à tabela 1 para que pudessem se basear.

Após a conclusão dos gráficos, foi realizada uma discussão acerca das diferenças regionais da produção da soja, quando os educandos puderam refletir o porquê da localização das produções. 
O objetivo do segundo encontro foi o de trabalhar com a cartografia temática através de mapas coropléticos. Essa atividade possibilitou a introdução dos elementos básicos de cartografia que compõe o mapa como escala, título, legenda, orientação e elaboração.

Foi solicitado que a turma se dividisse em dois grupos, e foi apresentado um mapa base em forma de maquete, feito de isopor, para que a atividade fosse realizada. Após a divisão dos grupos, e com auxílio dos dados da FAO - ONU, um grupo ficou com a produção de soja em escala mundial e outro com o consumo de carne per capita, também em escala mundial. Dessa forma, eles puderam realizar o trabalho manual, fazendo uso de tintas e desenvolvendo tonalidades necessárias para as maquetes como pedem os mapas coropléticos.

Após o término da atividade pelos dois grupos houve uma discussão dos resultados e foi possível fazer a comparação entre os dados em escala brasileira e mundial. Além disso, os educandos debateram os aspectos socioeconômicos relacionados à produção e ao consumo de soja e carne. Para finalizar as oficinas, houve a realização de uma avaliação com os alunos por meio de um questionário, e foi possível tornar reconhecido o que os alunos acharam das atividades que foram propostas através da prática envolvida.

\section{RESULTADOS}

A discussão realizada no primeiro dia em relação à reflexão retirada do Atlas da Carne (HENRICH BÖLL STIFTUNG FOUNDATION, 2016) gerou diversos questionamentos por parte dos alunos, resultando em debates pertinentes sobre a soja e carne.

Os resultados obtidos podem ser observados nas figuras 2 e 3 , que mostram os gráficos construídos pelos educandos. Durante a construção, notou-se uma grande dificuldade em questões matemáticas, principalmente com a leitura dos números e dificuldade de inserir os dados nos eixos dos gráficos. Apesar das visíveis dificuldades encontradas pelos educandos houve uma construção mútua de aprendizado, e eles buscaram ajudar uns aos outros.

No segundo dia, houve certa dificuldade em relação à disposição dos elementos no mapa devido aos questionamentos vindos por parte dos educandos, principalmente sobre escala e orientação. A troca de conhecimentos entre a turma ficou evidente, pois trabalhando em grupos eles puderam chegar a um resultado satisfatório de aprendizagem e interação. As atividades realizadas no segundo encontro podem ser observadas nas figuras 4 e 5.

Em relação ao questionário proposto aos educandos, é possível analisar através da figura 6 que os alunos entenderam facilmente o tema proposto e isso foi perceptível nas atividades retornadas por eles. Além disso, os gráficos demonstram (Figura 7) que os alunos gostaram de participar das oficinas didáticas. 
Figura 2 - Gráfico construído pelos alunos sobre a série histórica da produção de soja em toneladas, (1) regiões, norte, nordeste e sudeste

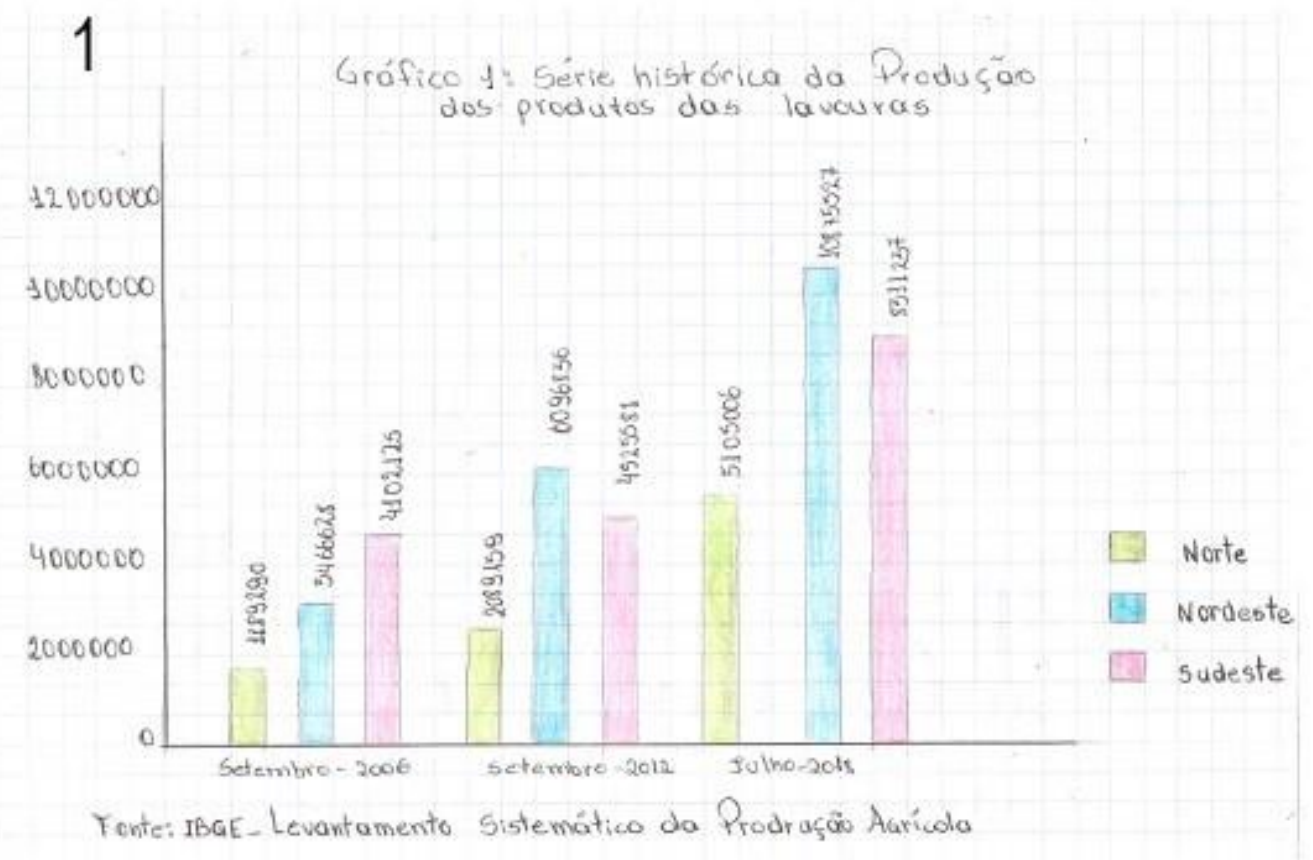

Fonte: IBGE (2018).

Figura 3 - Gráfico construído pelos alunos sobre a série histórica da produção de soja em toneladas (2) região sul e centro oeste

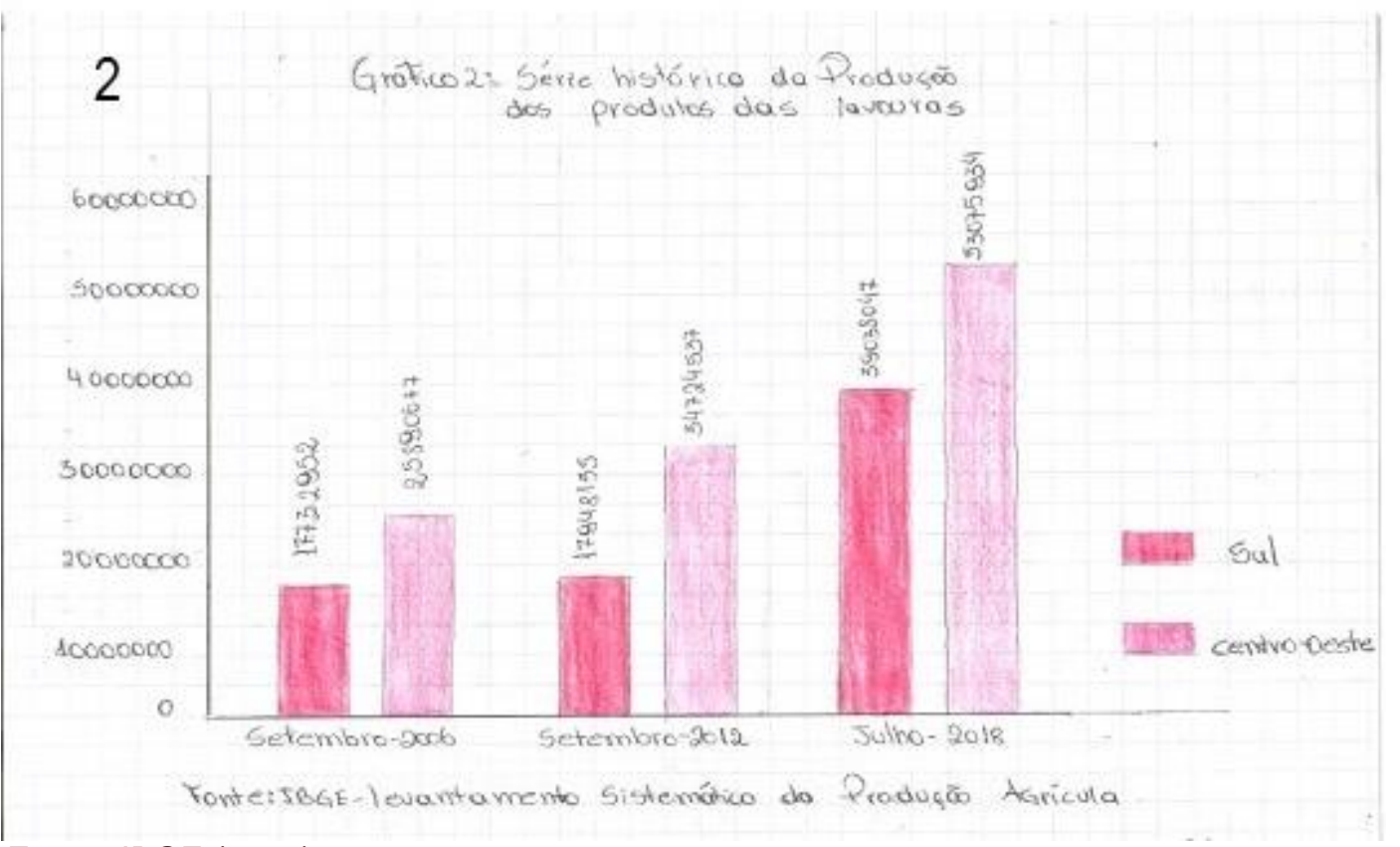

Fonte: IBGE (2018). 
Figura 4 - Maquete em escala mundial construída pelos alunos, da produção de soja em toneladas, no ano de 2014

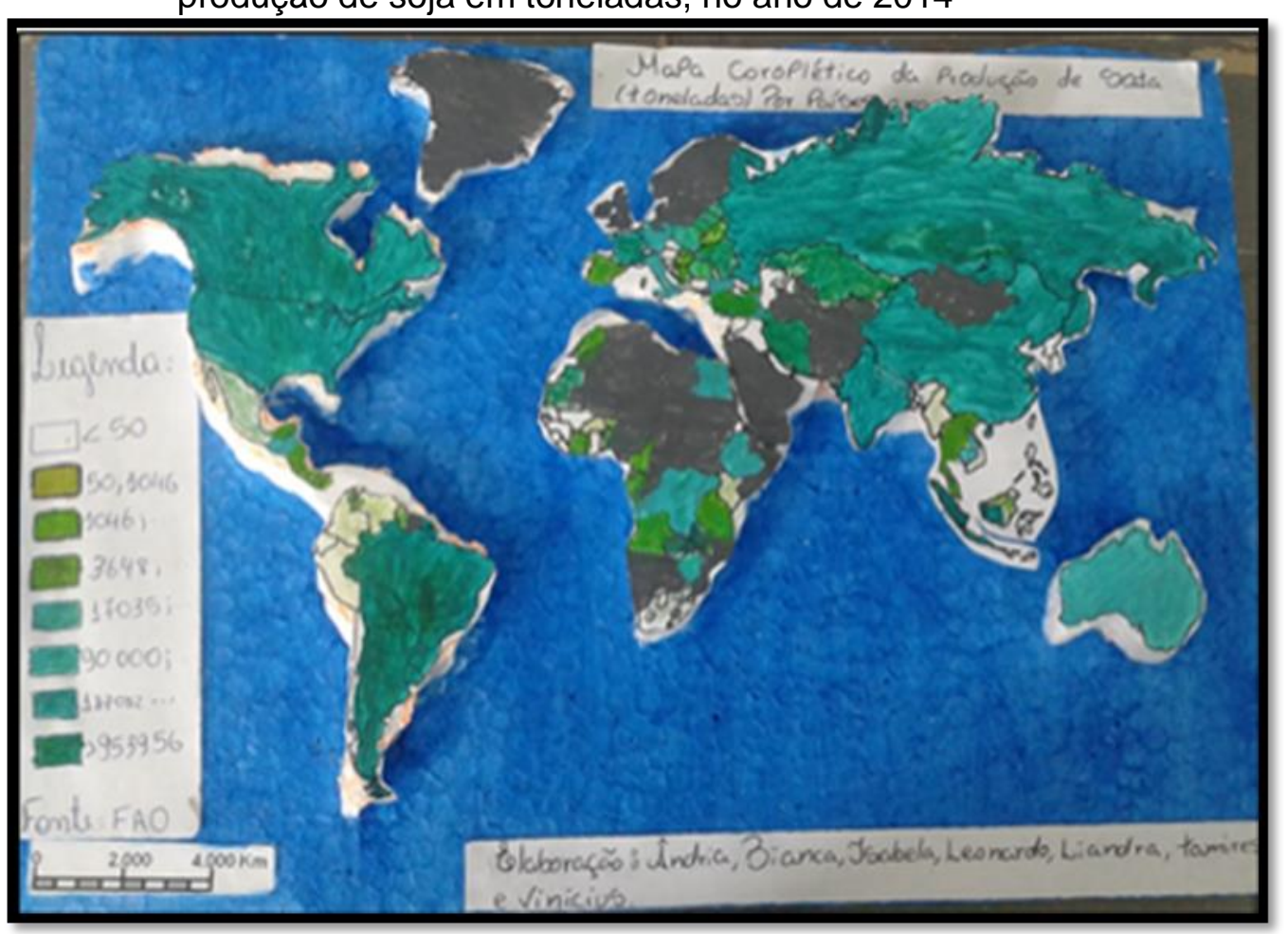

Fonte: FAO (2013).

Figura 5 - Maquete em escala mundial construída pelos alunos, do consumo de carne per capita em 2009

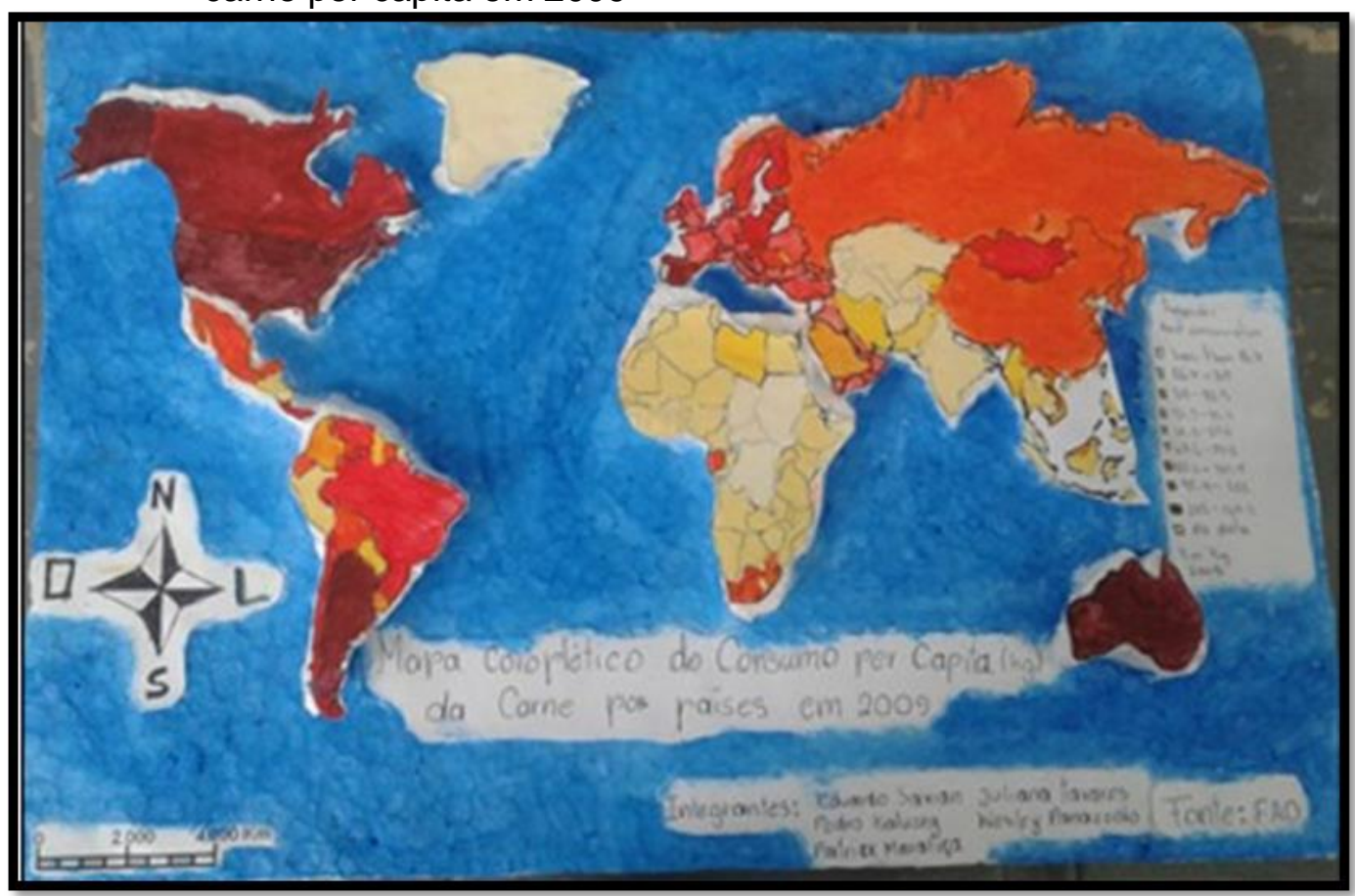

Fonte: FAO (2013). 
Figura 6 - Resultado do questionário

\section{Você compreendeu facilmente o tema proposto?}

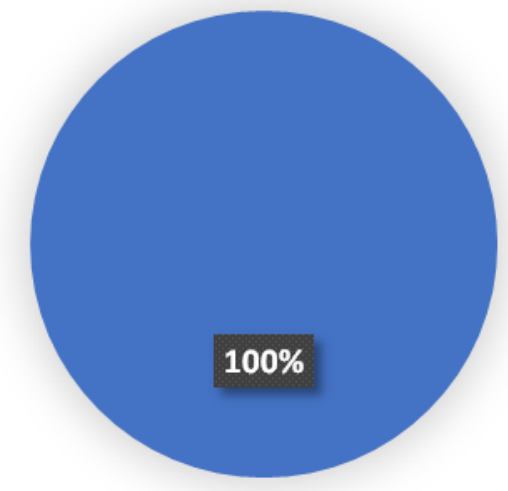

Fonte: os autores, 2018.

Figura 7 - Resultado da pergunta 2 do questionário

\section{Você gostou de participar das atividades que foram propostas?}

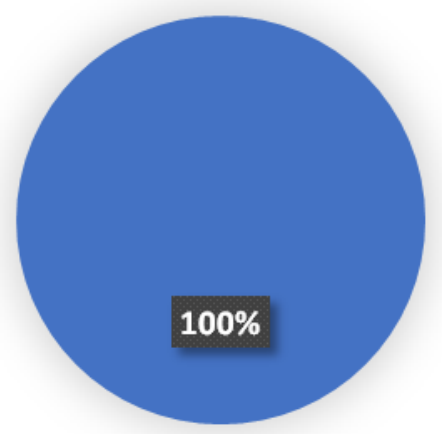

Fonte: os autores, 2018.

Através da figura 8, aproximadamente $10 \%$ dos educandos não possuíam 0 conhecimento de gerar gráficos a partir de tabelas. Através do diálogo, eles esclareceram que a grande maioria já havia realizado alguma atividade semelhante, principalmente a turma do terceiro ano do ensino médio diurna, mas que nenhuma atividade tinha sido aprofundada através dessas atividades. Juntamente, através da figura 9, eles confirmaram que o tema foi importante para a compreensão da disciplina de geografia, o que torna visível a importância da interdisciplinaridade. 
Figura 8 - Resultado do questionário

\section{Você já possui conhecimentos de como} gerar gráficos a partir de tabelas e como utilizar em trabalhos de sala de aula?

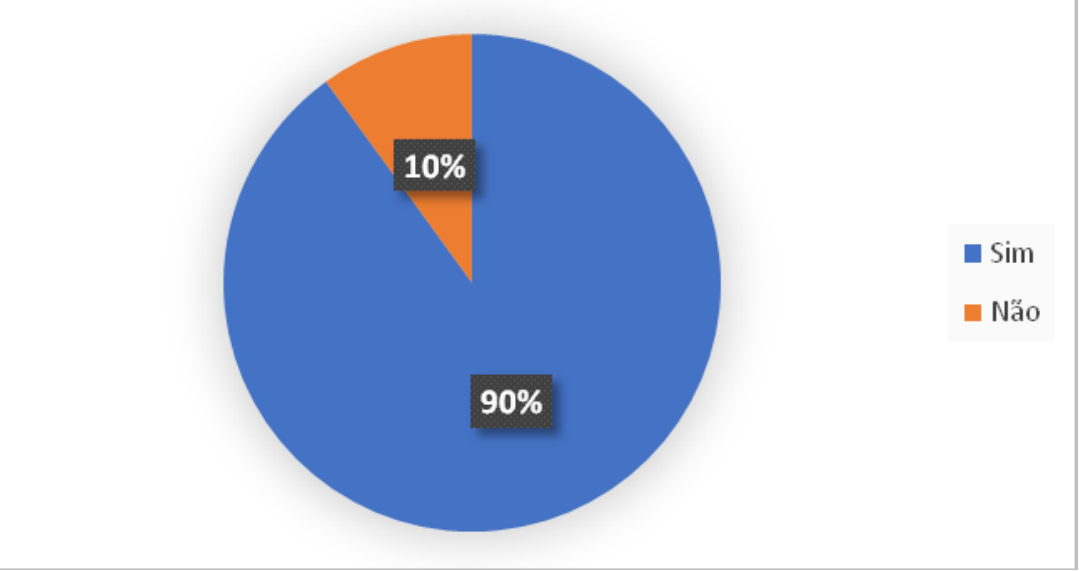

Fonte: os autores, 2018.

Figura 9 - Também resultado do questionário

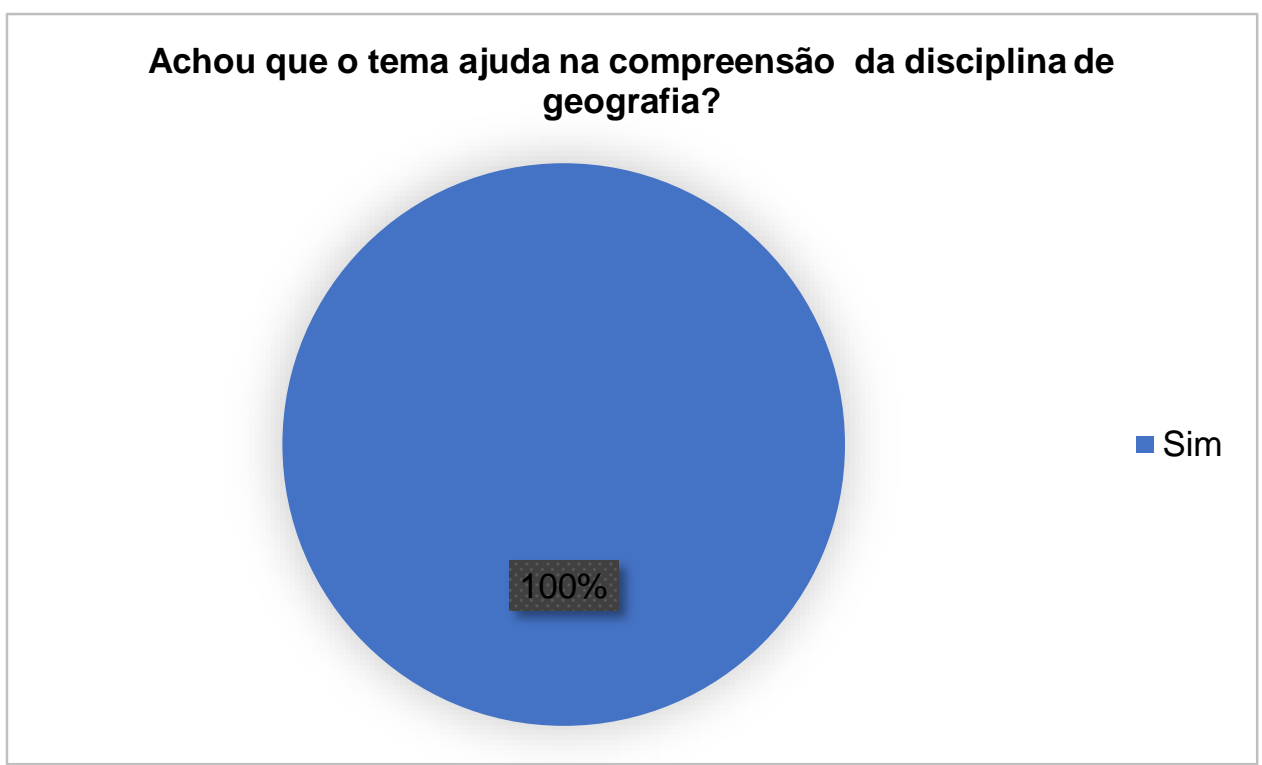

Fonte: os autores, 2018.

\section{CONSIDERAÇÕES FINAIS}

Visto a dificuldade em certos aspectos na construção de gráficos e mapas e na interpretação de tabelas, essa atividade proporcionou o conhecimento sobre o tratamento das informações geográficas, já que os assuntos são pouco estudados pelos alunos na educação básica. Do mesmo modo, trouxe novas perspectivas acerca dos seus conhecimentos prévios.

Foi possível, através das oficinas realizadas, compor novos campos de conhecimentos construtivos para o desenvolvimento das reflexões críticas sobre os assuntos da soja e da 
carne, que são tão importantes para entender o processo da agropecuária em escala brasileira e mundial.

Diante disso, concluímos que é necessário trabalhar com tabelas, gráficos e mapas a fim de fornecer aos alunos subsídios que amenizem as dificuldades no tratamento e interpretação de dados, assim, fortalecendo a área de Geografia e tornando alunos críticos leitores de informações e de mundo.

\section{REFERÊNCIAS}

FAO - Food and Agriculture Organization of the United Nations. Current worldwide annual meat consumption per capita. 2013. Disponível em:

http://faostat.fao.org/site/610/DesktopDefault.aspx?PagelD=610\#ancor. Acesso em: 23 jul. 2018.

FRANCISCHETT, M. N. A cartografia no ensino-aprendizagem da geografia. 2004.

Disponível em: www.bocc.ubi.pt/pag/francischett-mafalda-representacoes-cartograficas.html. Acesso em: 24 jan. 2020.

FREIRE, P. Pedagogia da autonomia: saberes necessários a prática educativa. Rio de Janeiro: Paz e Terra, 2014.

HENRICH BÖLL STIFTUNG FOUNDATION. Atlas da carne. Rio de Janeiro: Henrich BöllStiftung Foundation, 2016.

IBGE. Bases e referências. Disponível em: https://mapas.ibge.gov.br/bases-ereferenciais/bases-cartograficas/malhas-digitais. Acesso em: 18 ago. 2019.

IBGE. Sistema IBGE de recuperação automática. Disponível em: https://sidra.ibge.gov.br/home/ipca15/brasil. Acesso em: 23 jul. 2018.

INSTITUTO ESTADUAL LUIZ GUILHERME DO PRADO VEPPO. Projeto político pedagógico. Santa Maria: I. E. Luiz Guilherme do Prado Veppo, 2018.

JOLY, F. A cartografia. Campinas: Papirus, 1997.

LACOSTE, Y. A geografia: isso serve em primeiro lugar para fazer a guerra. São Paulo: Papirus, 1988.

LEAL, C. L. C.; CARDOSO, E. S.; ROCHA, A. M. Ensino de geografia, informação e cartografia: uma atividade de extensão integrando universidade-escola. In: SILVA, C. N.; CAETANO, V. N. S.; OLIVEIRA NETO, A. (org.). Ensino de geografia e representação do espaço geográfico. Belém: GAPTA/ UFPA, 2013. p. 187-204.

SANTOS, C.; PEDROTTI, A.; MATOS, A. L.; SANTANA, A. P. S. A cartografia e o ensino da geografia. Revista Geográfica da América Central, Costa Rica, n. esp., p. 1-15, 2. sem. 2011.

SILVA, A. F. A. Leitura e interpretação de mapas e gráficos: uma estratégia na prática cartográfica, Paraná. 2007. Disponível em:

http://www.gestaoescolar.diaadia.pr.gov.br/arquivos/File/producoes_pde/artigo_aparecida_fa tima_alves.pdf. Acesso em: 2 jul. 2019.

SILVA, E. S.; MELO, J. A. B. Leitura e produção de gráficos como recurso para compreensão do conteúdo população brasileira nas aulas de geografia. In: ENCONTRO NACIONAL DE INICIAÇÃO À DOCÊNCIA, 6., 2017, Campina Grande, PB. Anais [...]. Campina Grande: UEPB, 2017. p. 1-11. Disponível em: 
https://www.editorarealize.com.br/revistas/eniduepb/trabalhos/TRABALHO_EV100_MD1_SA 5_ID255_22112017184411.pdf. Acesso em: 2 jul. 2019.

SILVA, V.; MUNIZ, A. M. V. A geografia escolar e os recursos didáticos:o uso das maquetes no ensino-aprendizagem da geografia. Geosaberes, Fortaleza, v. 3, n. 5, p. 62-68, jan./jun. 2012.

Recebido: setembro de 2019.

Aceito: fevereiro de 2020. 